\title{
UNILATERAL BUDDING IN NEW VESSEL FORMATION IN THE EYE*†
}

\author{
BY \\ I. C. MICHAELSON \\ Department of Ophthalmology, Hadassah Medical Organization, Jerusalem, Israel
}

THE ophthalmologist is privileged to follow the formation of new vessels because of the frequency with which this occurs in the eye and because of the availability to him of facilities for precise examination.

The purpose of this study is to report an interesting phenomenon frequently seen in the course of new vessel production in the eye. The process of stimulation or inhibition of new vessel formation results in the appearance of fine vascular twigs on only one side of the parent vessel, the other side being free of such budding. The side of the parent vessel to show budding is determined by the location of the exciting or inhibiting factor. The following examples are taken from the retina, cornea, conjunctiva, and vitreous:

Fig. 1 illustrates the process of new vessel formation in the developing retina of a 56-day-old cat foetus injected with Indian ink. The budding of new vessels is taking place from only one side of the vein, that remote from the neighbouring artery. It can be assumed that the oxygen concentration in the retina is less at the side of the vein remote from the local artery. After the vein crosses the artery, the budding takes place from its other side.

Fig. 2 shows vessels in the limbal region of a rabbit cornea injected with Indian ink. These vessels have been produced in response to an experimental wound of the cornea not shown in the figure but lying in the direction (x). The budding is taking place from the side of the parent vein directed towards the corneal wound from which presumably the vasogenic factor emanates.

Fig. 3 shows a corneal vessel in a case of central keratitis. The new vessel budding is taking place from the side of the parent vessel directed towards the inflammatory area from which the stimulus has arisen.

Fig. 4 shows a limbal bleb following a successful Elliot's operation. As usual in such cases there are no fine vessels on or in the immediate neighbourhood of the bleb. A conjunctival vessel has a dense area of budding confined to the side remote from the aqueous influence.

Fig. 5 (overleaf) shows a fistulizing area in the centre of the cornea. The vessels are keeping away from the region of the cornea in which aqueous is present. Budding from the large vessel seen in the cornea above is confined to the side of the vessel remote from the fistulizing area.

Fig. 6 (overleaf) shows a case of Eales's disease with neovascularization in the vitreous. A frond of fine twigs is growing from that side of the larger vessel which is directed towards the centre of the vitreous.

*Received for publication July 11, 1955

+ This work was supported by a grant from the Arnold Reuben Fight for Sight Fund of the National Council to Combat Blindness, Inc., New York. 


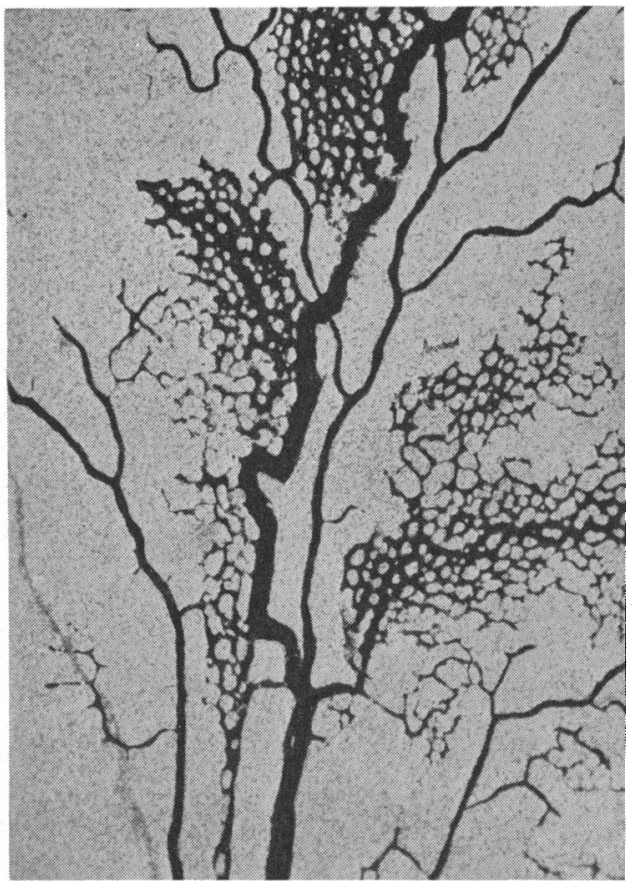

Fig. 1.-Injected retina of 56-day-old cat embryo showing capillary growth from veins confined to side of vein away from artery.

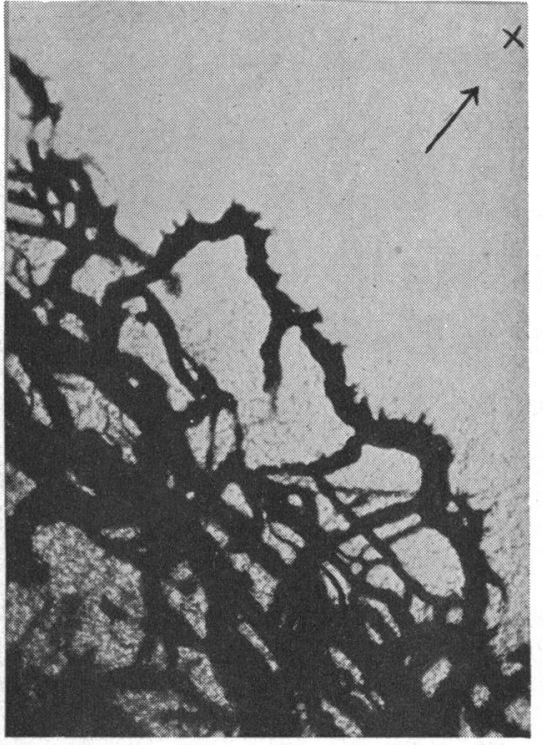

Fig. 2.-New vessel formation in limbus of cornea in response to an experimental wound situated in direction $X$. Vessels injected with Indian ink. Budding is taking place exclusively from the side of the parent vein directed towards the corneal wound from which the vasogenic factor presumably emanates.

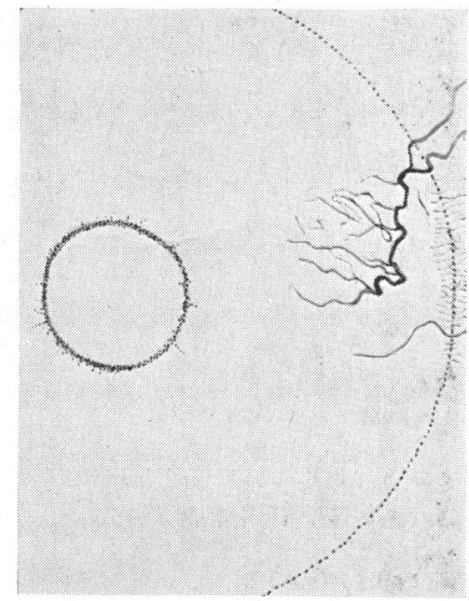

FIG. 3.- Corneal vessel in a case of central keratitis. The new vessel budding is taking place entirely from the side of the parent vessel directed towards the inflammatory area from which the stimulus emanates.

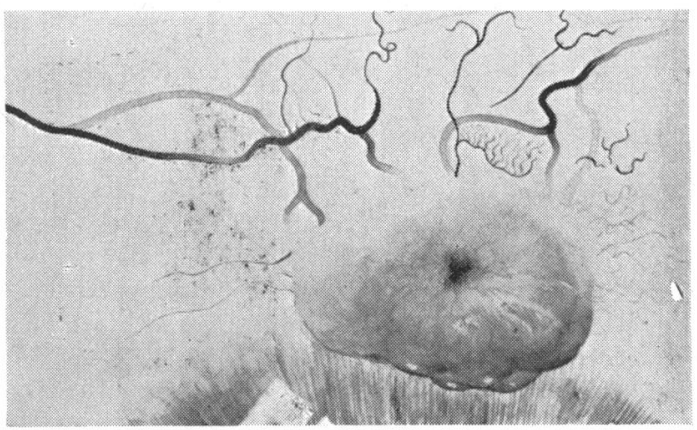

FIG. 4.-Limbal bleb after successful Elliot's operation. No fine vessels on or in immediate neighbourhood of bleb. Conjunctival vessel has dense area of budding confined to side remote from aqueous influence. 


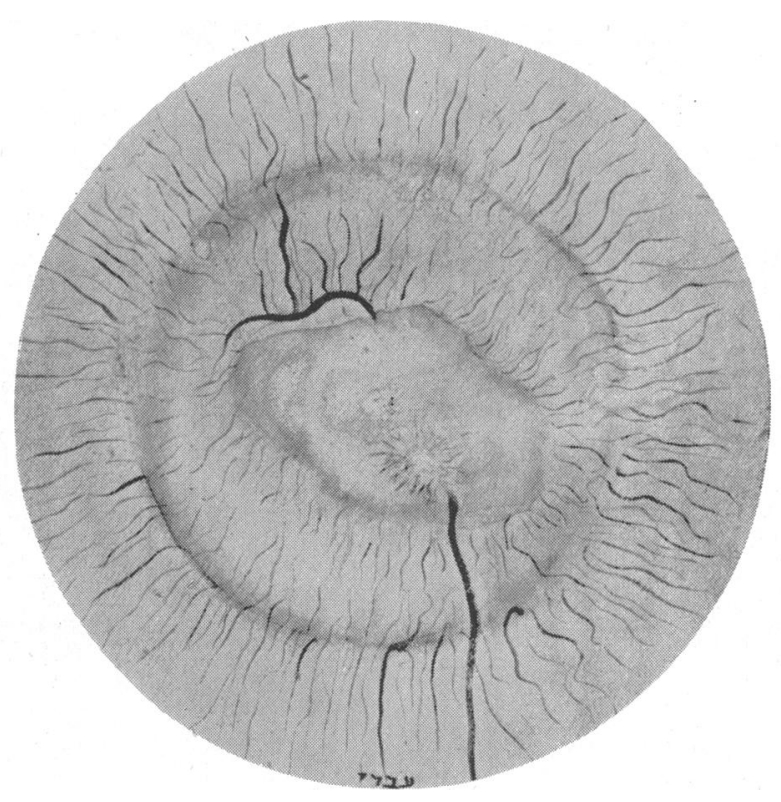

Fig. 5.-Fistulizing area in centre of cornea. Budding from the large vessel seen in the cornea above is confined entirely to side of vessel remote from fistulizing area.

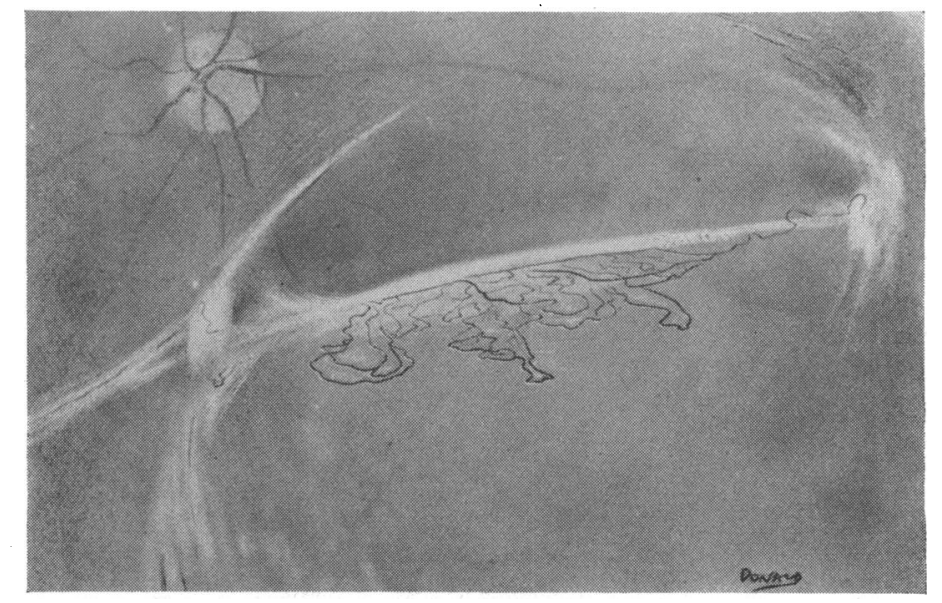

FIG. 6.-Case of Eales's disease with retinitis proliferans. A frond of fine twigs is growing from that side of the larger vessel which is directed towards the centre of the vitreous.

\section{Discussion}

These cases are typical of many others which have been observed. If they are considered as a group the following conclusions may be drawn:

(1) The factor exciting or inhibiting new vessel growth is a substance in the tissues.

(2) The concentration of the factor at any point in an avascular area is determined by the distance of that point from the source of the factor. 
(3) A certain concentration of the factor is required to affect the potential parent vessel.

(4) The concentration of the factor falls rapidly in the neighbourhood of the new vessels it has succeeded in producing.

The unilateral budding would appear to contravert the conception that new vessel formation in the cornea is determined by changes in the tissue pressure (Cogan, 1949). It is difficult to conceive changes in tissue pressure following the line of the tortuous vessels seen in Figs 2, 3, 4, and 5.

It is not known whether the vasogenic factor is the same in all the processes indicated above. The factor determining new vessel growth in the developing retina appears to be oxygen concentration (Ashton, 1954). Aqueous fluid appears to have an inhibiting influence on new vessel growth, as evidenced by the general absence of new vessel growth after iridectomy and by the absence of fine vessels in the neighbourhood of a fistulizing wound of the cornea or limbus.

\section{Summary}

(1) The phenomenon of unilateral new vessel budding from a parent vessel is described in various tissues of the eye.

(2) This phenomenon would appear to support the conception that new vessel budding is conditioned by a diffusible factor or factors present in the tissues.

\section{REFERENCES}

Ashton, N., WARD, B., and Serpell, G. (1953). British Journal of Ophthalmology, $37,513$. Cogan, D. G. (1949). Arch. Ophthal. (Chicago), 41, 406. 